\title{
Task-based Learning Research and the Cognition Hypothesis: The Case of Task Complexity
}

\author{
Ebrahim Ghorban Mohammadi \\ Department of English, Islamic Azad University, Khorramabad branch, Lorestan, Iran \\ Email: ebrahimqm1354@yahoo.com \\ Mohammad Hossein Yousefi (Corresponding Author) \\ Department of English, Islamic Azad University, Bonab Branch, Bonab, Iran \\ Email: mhh.yousefi@gmail.com \\ Akbar Afghari \\ Department of English, khorasgan (Isfahan) branch, Islamic Azad University, Isfahan, Iran \\ Email: Afghay@yahoo.com
}

\begin{abstract}
In this paper, the construct of task complexity and its significance in grading and sequencing of pedagogic tasks are discussed. Then, mention will be made of different models and criteria for estimating task complexity. After that, the most comprehensive model (Robinson's Triadic Framework or The Cognition hypothesis) will be discussed in great details and the research done in this framework will be outlined. Finally, the role of the Task Complexity in grading and sequencing pedagogical tasks will be touched upon.
\end{abstract}

Index Terms - task-based learning, Cognition Hypothesis, task complexity, grading, sequencing

\section{TASK-BASED LANGUAGE TEACHING}

Task-based Teaching, is argued that, creates more favorable conditions for the development of second language ability than does an approach that focuses on the explicit teaching and learning of the rules of the language alone (Long, 1985; Prabhu, 1987; Rahimpour, 1997, 1999; Robinson, 1995a, 2001b, 2011). Recently, there has been a growing interest in task-based language teaching (see Bygate 1999; Bygate et al., 2001; Crabbe 2007; Long 2007; Skehan 1998a; Van den Branden 2006; Willis and Willis 2001). The rationale for task-based teaching (TBT) comes from different camps; Ellis (2003) provided psycholinguistic rationale, whereas, Skehan (1998a, 1998b, 2002, 2003a, 2003b) took a more cognitive approach to advocate it (see Ellis, 2000). In Widdowson's terms (2003), Skehan provided the most comprehensively theoretical rationale for task-based learning. Skehan (1998a) pointed out that "as an approach to instruction, TBT is theoretically defensible and practically feasible. The assumption here, then, is the fact that transacting tasks will engage naturalistic acquisitional mechanisms, cause the underlying interlanguage system to be stretched, and drive development forward". (P. 95).

Robinson (2003b) forcefully argues that task-based pedagogy facilitate the cognitive processes involved in second language production (performance) and acquisition (development), and their relationship.

Prabhu (1987), one of the great supporters of TBLT, believes that "a task is an activity which require learners to arrive at an outcome from given information through some process of thought, and which allowed teachers to control and regulate that process'. Bygate et al., (2001) put forward the following definition for a task: "a task is an activity which requires learners to use language, which emphasis on meaning, to attain an objective". Yet, more recently, Tavakoli and Foster (2008) define a task as "anything that classroom language learners do when focusing their attention primarily on what they want to say to others or what others are trying to say to them". However, the definition of task remains problematic in SLA and language pedagogy (for more on problems of task definitions see Skehan et al., 2001; Tavakoli and Foster, 2008).

Task Complexity

Robinson (2001b, 2005, and 2011) argues that task complexity is the result of the attentional, memory, reasoning, and other information processing demands imposed by the structure of the task to the language learner. Task complexity, differences in intrinsic cognitive processing demands of tasks, will explain within-learner variation in successfully completing any two tasks (such as doing simple addition versus calculus, or doing the simple versus complex intentional reasoning task (Robinson, 2007).

Ellis (2003) believes that task complexity is the extent to which a particular task is inherently easy or difficult. Different dimensions of task complexity are code complexity, cognitive complexity, and context dependence (P.351). Robinson (1995)) lists three theoretical frameworks for task complexity. According to him, the theoretical framework 
for the proposed task complexity is based on research into first language acquisition (e.g., Brown \& Bellugi, 1964), research findings from second language development (Meisel, 1987), and functional linguistic theory (Givon, 1989).

It is widely accepted idea that research into complexity of second language tasks is necessary to pedagogical decisions regarding the grading and sequencing of tasks for the purposes of syllabus design (Gilabert, 2005, 2007; Long 2007; Mortazanejad, 2008; Rahimpour 1997, 1999; Robinson, 1995a, 2001b, 2003b, 2005a, 2007a, 2007a; Robinson and Gilabert 2007; Van Den Branden 2006).

As pointed out by Gilabert (2005), task complexity is the result of the preoccupation with grading and sequencing tasks in a principled way in a task-based syllabus. Thus, information about the effects of task complexity on language production and interlanguage development are important because they help syllabus designers to design tasks from simple to complex, in a way that they gradually approximate real world tasks. More importantly, Robinson (2001b) argues that cognitive complexity is a robust and manipulable influence on learner production, and is therefore a feasible basis for design and sequencing decisions which operationalized a task-based syllabus.

Of three sets of factors discussed in task-based teaching (task complexity, task conditions, and task difficulty), Robinson (2003b) reiterates the fact that complexity differentials should be the sole basis for proactive pedagogic task sequencing in task-based approaches to syllabus design. However, Candlin (1987) and Nunan (1989) have based arguments for difficulty variables, such as motivation to perform, and anxiety about performing task, in sequencing and grading tasks. Still, some others, such as Prabhu (1987) have argued that task sequencing should be based on differences in task conditions (e.g., from closed, information gap, to open opinion gap tasks).

Task Complexity and Interlanguage Development

Robinson's Cognition Hypothesis (2001b, 2003b, 2005a, 2007) claims that increasing the cognitive demands of tasks along certain dimensions will; (a) push learners to greater accuracy and complexity of L2 production in order to meet the greater functional and conceptual communicative demands they place on the learner; (b) promote interaction, and heightened attention to and memory for input, so increasing learning from the input; as well as (c) longer term retention of input; and that (d) performing simple to complex sequences will also lead to automaticity and efficient scheduling of the components of complex L2 task performance.

More importantly, the Cognition Hypothesis predicts that along resource-directing dimensions more interactive complex tasks will result in greater amounts of interaction, and negotiation for meaning. Following Long (1996), The Cognition Hypothesis claims that such negotiation provides a content for attending to problematic forms in the input and output, and additionally that on complex versions of tasks, there will be greater attention to, and uptake of forms made salient during provision of reactive Focus on Form techniques such a recasts. Alternatively, where proactive Focus on Form is provided, for example in the form of premodified input to the task, then it similarly claims there will be greater use of this on complex, versus simpler task versions (Robinson and Gilabert, 2007).

\section{Different Models for Determining Task Complexity}

There have been a wide variety of models or criteria for estimating task complexity in the literature on task complexity; each highlighting one dimension of a task at hand (Anderson \& Lynch, 1988; Brindley, 1987; Brown \& Yule, 1983; Candlin, 1987; Candlin and Nunan, 1987; Long, 1985; Prabhu, 1987; Rahimpour, 1997, 1999; Robinson 2001b, 2007a). However, it seems to the present researcher that the latter one is more comprehensive as well as theoretically motivated and practically oriented. Because of the limitation of scope, some of these models briefly will be discussed but the Robinson's model (2001b) will be given the focal attention with respect to the research has been done in the field:

Brindley (1987) suggested that the following factors will determine the complexity of what the learner has to do:

-Relevance:

Is the task meaningful and relevant to the learner?

-Complexity:

How many steps are involved in the task?

How complex are the instruction?

What cognitive demands does the task make on the learner?

-Amount of context provided prior to the task:

How much prior knowledge of the world, the situation or the cultural context is assumed in the way the task is framed?

-Processability of language of the task:

Is the language that learners are expected to produce in line with their processing ability?

-Amount of help available to the learner:

How much assistance can the learner get from the teacher, other learners, books or other learning aids?

-Degree of grammatical accuracy/ contextual appropriacy:

How 'standard' does the task require learners to be?

Time available to the learner;

How long does the learner have to carry out the task?

Brown and Yule (1983) have devoted a noticeable attention to task difficulty. They suggested that listening tasks can be graded with reference to speaker, intended listener, content, and support. When listening to a tape, the fewer the 
speakers, the easier the text will be to process. Following one speaker will be easier than following two, and so on. With respect to the intended listener, they propose that texts, especially' authentic' texts which are not addressed to the listener, may be difficult to process. As far as 'content' is considered, they suggest that specialized vocabulary which is unfamiliar can be a source of difficulty. Finally, by 'support' they mean the provision of visual cues to a listener that facilitates the cognitive load of the listening task.

Prabhu (1987) provides the following factors for determining difficulty:

1. Information provided: the amount and type of information handled will affect difficulty

2. Reasoning needed: the number of steps or cognitive operations (e.g. deduction, inference, or calculation) will affect difficulty.

3. Precision needed: difficulty increases with the degree of precision called for.

4. Familiarity with constraints: learners' knowledge of the world and familiarity with purposes and constraints will affect difficulty.

5. Degree of abstractness: working with concepts is more difficult than working with the names of objects or actions.

Anderson and Lynch (1988) identify a range of factors which influence difficulty;

- the sequence in which information is presented;

- the familiarity of the listener with the topic;

- the explicitness of the information contained in the text;

- the type of input;

- the type and scope of the task to be carried out;

- The amount of support provided to the listener.

Candlin (1987) proposed a set of criteria by which tasks might be selected and graded. These are:

-cognitive load: this concerns the general complexity of the content of the task, including the naturalness of the sequence it may be required to follow;

-communicative stress: more stressful tasks are seen as those which involve pressure which comes from the interlocutor, either because he/she is a native speaker or because of superior knowledge or proficiency;

-particularity and generalizability: this concerns the clarity of the goal of the task, as well as the norms of interpretation;

-process continuity: this derives from the familiarity of the task as well as the learner capacity to relate the task to tasks they are familiar with;

-code complexity and interpretative density: the first concerns the complexity of the linguistic code, while the latter is concerned with the complexity of the operations which need to be carried out on such a code.

Skehan (1998a, 1998b) has proposed the following criteria for determining task difficulty:

1. Code complexity

-linguistic complexity and variety

-vocabulary load and variety

-redundancy and density

2. Cognitive complexity

Cognitive familiarity

-familiarity of topic and its predictability

-familiarity of discourse genre

-familiarity of task

Cognitive processing

-information processing

-amount of 'computation'

-clarity and sufficiency of information given

-information type

3. Communicative stress

-time limits and time pressure

-speed of presentation

-number of participants

-length of texts used

-type of response

-opportunities to control interaction.

Candlin and Nunan (1987) have also suggested that activities can be graded according to the general cognitive demands they make. Their scheme has four levels as follows:

1. Attending and recognizing; the learner's ability to notice what kind of input he or she is being confronted with.

2. Making sense; the learner's ability to make sense of the input as a particular example of language, determining, for example, what particular language it is, how it is organized, how it is classified and patterned.

3. Going beyond the information given; the learner's ability to hypothesize, infer, and make judgments, for example, about the underlying meaning of the test. 
4. Transferring and generalizing; the learner's ability to extrapolate from any particular texts of same type, genre, and purpose, or transferring the information gained from and about a particular text to other texts that may be of other quiet different structure, channel and purpose.

\section{TASK COMPLEXITY AND THE COGNITION HyPOTHESIS}

As stated earlier, in a series of arguments put forward by Robinson, he proposed the most comprehensive criteria for determining task complexity (Robinson 2001b, 2003b, 2005a, 2007a, 200c). It should be mentioned that his criteria, also called Triadic Componential Framework or The cognition Hypothesis, is not free of critique; Kuiken and Vedder (2007) have questioned the validity of the framework as being not empirically researchable and operationally feasible. Unlike Kuiken and Vedder (2007), the present researcher assumes some authority to this framework and believes that further research is needed to investigate some dimensions of the Cognition Hypothesis.

Robinson (2001b) pointed out that the development of theoretically motivated, empirically substantiable, and pedagogically feasible sequencing criteria has long been acknowledged as a major goal of research aimed at operationalizing task-based approaches to syllabus design. To this end, he proposed distinctions between cognitively defined task complexity, learner perceptions of task difficulty, and the interactive conditions under which tasks are performed. Robinson (2001b) strongly argued that Task Complexity is the result of the attentional, memory, reasoning, and other information processing demands imposed by the structure of the task on the language learner. These differences in information processing demands, resulting from design characteristics, are relatively fixed and invariant. Task complexity will aid explain within learner variance when performing any two tasks. It is, also, argued that the cognitively simpler tasks will involve a lower error rate, and/or be completed faster. (P. 29).

The criteria proposed by Robinson (2001b, 2003b, 2005a, 2007a) are divided into two categories; resource-directing dimensions and resource-dispersing dispersing dimensions. Resource-directing dimensions are those in which the demands on language use made by increases in Task Complexity, and the increased conceptual demands they implicate, can be met by specific aspects of the linguistic system. For example, tasks which differ along the Here-and-Now versus There-and-Then dimension obviously require the learner to distinguish between the temporality of reference (present versus past), and to use distinct deictic expressions (this, that, here, there) to indicate immediately present, versus absent object (See Rahimpour, 1997).

It is argued that increasing complexity along these dimensions therefore has the potential to direct learners' attentional and memory resources to the way that the L2 structures and code concepts, so leading to interlanguage development (Robinson, 2003b, 2007a, 2007c; Robinson and Gilabert 2007).

In contrast, increasing task complexity along the resource-dispersing dimensions does not direct learners to any specific aspects of language code which can be used to meet the additional task demands (Robinson, 2001b, 2003b, 2005a, 2007a). Taking planning time, or relevant prior knowledge away, or increasing the number of tasks that have to be performed simultaneously, simply disperses intentional resources. Although, increased along these resourcedispersing is important, since it stimulates the processing conditions under which real time language is often used, and practice along them, Robinson (2003b) argues that, facilitates real-time access to an already established and developing repertoire of language, rather than to facilitate new form-function and conceptual mapping in the L2.

In a more recent study, (Robinson, 2007a) adds $+/$ - perspective taking and makes distinction between three kinds of reasoning: +/- spatial reasoning, +/- causal reasoning, +/- intentional reasoning (see Table .3).

TABLE 1: THE TRIADIC COMPONENTIAL FRAMEWORK FOR TASK CLASSIFICATION-CATEGORIES, CRITERIA, ANALYTIC PROCEDURES, AND DESIGN CHARACTERISTICS (FROM ROBINSON 2007A)

\begin{tabular}{|c|c|c|}
\hline Task complexity (cognitive factors) & Task condition (interactive factors) & Task Difficulty (learner factors \\
\hline $\begin{array}{l}\text { (classification criteria: } \\
\text { Cognitive demands) } \\
\text { (classification procedure: } \\
\text { Information-theoretic analyses) } \\
\text { (a)Resource-directing variables making } \\
\text { cognitive/conceptual demands }\end{array}$ & $\begin{array}{l}\text { (classification criteria: } \\
\text { Interactional demands) } \\
\text { (classification procedure: } \\
\text { behavior-descriptive analyses) } \\
\text { (a) Participation variables making } \\
\text { interactional demands }\end{array}$ & $\begin{array}{l}\text { (classification criteria: ability } \\
\text { requirements) } \\
\text { (classification procedure: ability } \\
\text { assessment analyses) } \\
\text { (a) Ability variables and task- } \\
\text { relevant resource differentials }\end{array}$ \\
\hline $\begin{array}{l}+/ \text { - here and now } \\
+/ \text { few elements } \\
+/- \text { spatial reasoning } \\
+/ \text {-causal reasoning } \\
\text {-/+ intentional reasoning } \\
\text {-/+ perspective-taking }\end{array}$ & $\begin{array}{l}\text { +/- open solution } \\
\text { +/- one-way flow } \\
\text { +/-convergent solution } \\
\text { +/- few participations } \\
\text { +/- few contributions needed } \\
\text { +/- negotiation not needed }\end{array}$ & $\begin{array}{l}\mathrm{h} / \mathrm{l} \text { working memory } \\
\mathrm{h} / \mathrm{l} \text { reasoning } \\
\mathrm{h} / \mathrm{l} \text { task-switching } \\
\mathrm{h} / \mathrm{l} \text { aptitude } \\
\mathrm{h} / \mathrm{l} \text { field independence } \\
\mathrm{h} / \mathrm{l} \text { mind/intention-reading }\end{array}$ \\
\hline $\begin{array}{l}\text { (b) Resource-dispersing } \\
\text { Variables making } \\
\text { Performative/procedural demands }\end{array}$ & $\begin{array}{l}\text { (b) Participant variables } \\
\text { making interactant demands }\end{array}$ & $\begin{array}{l}\text { (b) Affective variables and state- } \\
\text { trait differentials }\end{array}$ \\
\hline $\begin{array}{l}+/ \text { planning time } \\
+/- \text { single task } \\
+/ \text { - few steps } \\
+/ \text { - independency of steps } \\
+/ \text { - prior knowledge }\end{array}$ & $\begin{array}{l}\text { +/- same proficiency } \\
\text { +/- same gender } \\
\text { +/- familiar } \\
\text { +/- shared content knowledge } \\
\text { +/- equal status and order } \\
\text { +/- shared cultural knowledge }\end{array}$ & $\begin{array}{l}\text { h/l openness to experience } \\
\text { h/l control of emotion } \\
\text { h/l task motivation } \\
\text { h/l processing anxiety } \\
\text { h/l willingness to communicate } \\
\text { h/l self-efficacy }\end{array}$ \\
\hline
\end{tabular}




\section{+/- FEW ELEMENTS}

The Cognition Hypothesis (Robinson 2001a, 2001b, and 2005a) states that identifying few easily distinguished elements within a task is simpler than identifying many similar elements (+/- few elements). It can be claimed that relatively few researches have investigated the $+/$ - few elements of The Cognition Hypothesis (see Robinson 1996). In an oral interactive task, Robinson (2001b) manipulated the factor $+/$ - few elements. The complex task prompted significantly more lexically varied speech than the simple task but neither structural complexity nor accuracy revealed any significant effects. Fluency decreased in the complex version.

Michel et al., (2007) have operationalized +/- few elements factor of task complexity. They hypothesized that increased cognitive task complexity along the resource-directing factor $+/$ - few elements will have a beneficial effect on the performance of L2 learners in that their speech will be more accurate and linguistically more complex . Fluency, they predicted that, will suffer from increased task complexity.

Michel et al., showed that complex tasks generally yielded a higher accuracy, as measured by the number of errors, omissions and the ratio of repairs to errors, while the percentage of repairs went in the opposite direction in the simple task, i.e., the percentage of repair is lower. They further found that structural complexity decreased, but lexical complexity increased in complex tasks. All of these studies are in direction of the Cognition Hypothesis (Robinson, 2001a) in that complex tasks lead to more accuracy and linguistic complexity at the cost of fluency.

Here-and-Now vs. There-and-Then

Rahimpour (1997) operationalized the resource-directing dimension of $+/$ - Here-and-Now as distinction between narratives performed when learners describe a series of event in the present tense while looking at pictures illustrating them (Here-and-Now), versus narratives performed from memory without looking at the pictures, and delivered in the past tense (There-and-Then). He found There-and-Then narratives were more accurate (in error-free T-units), and more dysfluent (Cited in Robinson, 2001b).

To operatioalize the Here-and-Now, There-and-Then dimension of complexity, Robinson (1995a) studied high beginner to intermediate level L2 learners of English from a variety of L1 backgrounds (Tagalog, Japanese, Korean, and Mandarin) performing narratives in the present tense, while they could view a series of wordless cartoon pictures described a humorous story (the Here-and-Now) versus performing the narratives from memory, after having viewed the picture prompts, in the past tense (the There-and-Then). In terms of task condition, this was a monologic, and so one way, open task. To establish tense, each participant was asked to begin by reading a short prompt describing the setting of the story (written in the present for here-and-Now, and the past for the Here-and-Then) before continuing the narrative in their words. Robinson (1995a) found significantly greater lexical complexity/density (percentages of lexical words per utterance) on the more complex task ( $\mathrm{p}<.5)$. There was a trend to more fluency on the simple task (in words per utterance, but not pauses per utterance), but differences in complexity (multipropositional utterances, and S-nodes per T-unit) were non-significant.

In a large scale study, Rahimpour (1997) operationalized three levels of complexity by including a narrative in the Here-and-Now, one in the There-and-Then, and one in the Here-and-Now/There-and-Then. Rahimpour hypothesized that the Here-and-now/There-and-Then narrative would be more complex than the other versions of the task. In this large scale study, fluency was measured by calculating the number of words per pause; structural complexity was measured via the number of S-Nodes per T-Unit; lexical complexity by calculating the percentage of lexical words; and accuracy by measuring the number of error-free units and target-like use of articles. Rahimpour's results showed that learners who carried out the most complex versions of the task were significantly less fluent, with no significant differences regarding either structural or lexical complexity, and with significant improvements with regard to error-free units but not target-like use of articles.

Gilabert (2007:218) found that increasing complexity along the $+/$ - Here-and-Now variable had positive effects on accuracy as measured by the percentage of self-repairs and the ratio of repaired to unrepaired errors, with no significant effects showing when measured by the number of error-free T-units or the target-like use of articles. Task complexity, as operationalized by There-and-Then; produce more accuracy and linguistic complexity (see Rahimpour 1997). Rahimpour (1997), also, concludes that tasks in There-and-Then condition force learners to produce syntactic mode of language rather than pragmatic one (In Givon, 1989 terms).

\section{+/- No Reasoning Demands}

Prabhu (1987) claims that tasks requiring selective information transmission +reasoning to establish causality, and justification of believes are more complex than tasks requiring non-selective information transmission, without these demands. Robinson (2005b) maintains that tasks which require no causal reasoning to establish event relations, and simple transmission of facts, compared to tasks which require the speaker to justify beliefs, and support interpretations of why events follow each other by giving reasons require expressions such as logical subordinators (so, because, therefore, etc.). In the case of reasoning about other people's intentions and beliefs, use of psychological, cognitive state verbs (e.g., know, believe, suppose, think) is required. Both of these, he argues, introduce complex syntactic complementation (Robinson 2007c).

In a one-way, interactive, closed dyadic task, Robinson (2000) has operationalized the +/- reasoning demands dimension of task complexity. In this study, one participant was asked to view a randomly ordered series of pictures showing characters performing different activities, and decide which chronological sequence they should be arranged 
into in order to depict a story, and also tell a partner (who could ask questions) the story that the series of pictures described. The partners were asked to sequence their own randomly ordered series of pictures in the order that corresponded to their partner's story. Reasoning demands were varied from the least and most complex. The simplest version does not require reasoning about the motives, intentions, or other thoughts of people. In contrast, in the most complex version, pictures can only be successfully sequenced if such motives, intentions and thoughts can be inferred (Robinson 2005a).

Following The Cognition Hypothesis, Robinson (2000) hypothesized that there would be more interaction and negotiation on the more complex task, as well as learners would look for more and more help in the input as task demands increased in complexity. This study demonstrated that more complex tasks would lead to more attention to, and incorporation of task relevant input.

Niwa (2000) also studied the effects of task complexity on language production along -/+ reasoning demands of complexity. To this end, she operationalized +dual task, and the -/+ reasoning demands dimensions of task complexity using four picture strips from the Wechsler Adult Intelligence Scale-Revised PA subset. She asked 22 Japanese L1 participants to decide on the sequence, and also tell the story in English. In this study, participants were instructed to tell the story described by the picture sets: there was no interlocutor participation, making it one-way task. Four stories used included the least complex and the most complex, and varied from simple to complex in reasoning demands.

Examining effects of individual differences (IDs) in intelligence, aptitude, and a reading span measure of working memory on accuracy, fluency and complexity, Niwa found that as tasks increase in their complexity, so IDs in cognitive abilities (intelligence, aptitude and working memory) increasingly differentiate performance. For the most complex task, higher working memory capacity and aptitude are associated with less fluency, as learners try to meet the demands of telling the story illustrated by the most complex set of pictures (Niwa, 2000).

In a more recent study, Robinson (2007c) has operationalized intentional reasoning dimension of task complexity. It was required, in this study, narrative tasks to be performed at three levels of conceptual/communicative complexity making resource-directing demands on L2 oral task performance. One participant decided on the correct sequence for pictures which had to be sequenced to complete a story, and then narrated this story to a participant who had to sequence the pictures in the order the narration he/she heard described. Robinson holds the view that, in this study, identifying the sequence requires successfully inferring and attributing those thoughts, intentions and psychological states to a main character appearing in each picture which cause them to perform a series of activates, with regard to other characters, in a particular picture-sequence order.

To assess the extent to which increasing the complexity of the intentional reasoning demands of the narrative tasks affected the listener's need to interact and negotiate meaning, Robinson (2007c) calculated the clarification requests, confirmation checks, and the number of turns taken. He demonstrated that there was a significant difference in the number of turns across tasks in the predicted direction with more turns and confirmation checks on complex versus simple tasks. (P. 204).

\section{Planning Time}

There has been a plethora of research with respect to giving the learners planning time before the performing of pedagogic tasks (Crookes, 1989; Ellis 2005; Foster and Skehan, 1996, 1999; Mortazanejad, 2008; Philip et al. 2006; Skehan 2001; Yuan and Ellis, 2003). Taken together, these studies suggested that planners showed gains in increased fluency and linguistic complexity but not conclusive results reported with respect to grammatical accuracy.

Plilip et al., (2006) stated that there are a number of different types of planning time. In pre-task or strategic planning, learners have the opportunity to plan before they produce language and carry out the task. In guided planning learners receive detailed instructions about how to plan, for example, by being advised to focus on syntax, lexis, content, or organization. Learners can plan individually or in small groups, pairs, or with a teacher .Likewise, Ellis (2003) makes distinction between online planning and strategic planning. The former examines how the planning that takes place during performance of a task affects production, whereas, strategic planning examines how planning prior to performance influences production.

Philip et al. (2006) investigated the relationship between pre-task planning and linguistic production in children's ESL classrooms. Philip et el. reported that in terms of interaction, the children's provision of feedback to each other was greater when they did not have anything to plan or when they had a short amount of planning time. In terms of fluency and accuracy, Philip et al. (2006) hypothesized that, there were no significant differences according to planning time.

Children's speech was significantly more complex after $5 \mathrm{~min}$ of planning, compared to no planning or 2 min planning. To sum up Philip et al. (2006) speculated that providing children with planning time did not necessarily result in more learning opportunities for the children, in terms of fluency and accuracy gains. In this study, fluency was measured according to the number of reformulations and false starts per turn. Accuracy was coded in terms of percentage of target-like communication units. Complexity was coded by amount of subordination or coordination, and percentage of words functioning as lexical verbs.

Yuan and Ellis (2003) compared the effects of pre-task and online planning on learner performance of a narrative task in a more systematic way. In pre-task planning condition learners were given 10 min to prepare the task and then performed it under time pressure. In the online planning condition, the learners were given no chance to prepare rather 
were allowed to perform the task in their own time. The results indicated that opportunities for online planning aided both accuracy and complexity but at the expense of fluency.

Crookes (1989) explored the consequences of giving learners ten minutes planning time prior to their completion of two information-gap tasks. He reported that planners produced language that was more complex and fluent than nonplanners, but no more accurate. He suggested that planners use planning time to complexify the task, hence leading, to a greater amount of subordination but with no greater accuracy with more challenging language used.

Ultimately, Skehan (2003: 396) concludes that "research has shown that giving learners the opportunity to plan before a task is done consistently produces greater complexity of language and greater fluency. These effects are dependable and strong, and imply that if one wants learners to draw upon more advanced language, and if one wants them to use this language with less hesitation and pausing, giving planning time is essential." (P. 396). The contribution of the studies with respect to planning time for the task complexity is the fact that having no planning time prior to the task performance imposes aatentional demands for the learners making their utterances more complex and less fluent (See Ellis, 2005).

\section{Prior Knowledge}

As rightly pointed out by Robinson (2001b), the facilitating effect of prior knowledge on task performance receives support from research outside the field of SLA as well as from within it for its effects on L2 reading and listening comprehension (e.g., Urwin, (1999).

A considerable body of research in cognitive psychology exists to support the idea that background knowledge (i.e., topic familiarity, domain knowledge) facilitates performance on a variety of cognitive task (Leeser, 2007). Chang (1999) found that topic familiarity led to significantly greater fluency, but had no effect on accuracy (error rate per $\mathrm{T}$-unit).

Skehan (1998a) noted that with regard to task demands, tasks based on familiar information make noticing more likely because unfamiliar information might overload a limited processing capacity and render noticing of certain forms less likely. Moreover, Lee (2007) hypothesized that the processing of a text with a familiar topic would demand less attentional recourses than with a less familiar topic, making more cognitive resources available to form. Robinson (2003a) sums it up that "research reports that greater levels of background knowledge contribute to efficiency of attentional allocation to input during reading, enabling richer textual interpretations, and, in turn, superior memory performance".

Topic familiarity has a demanding effect on the amount of meaning negotiation that occurs during task performance (Rahimpour and Hazar, 2006, 2007). In the same vein, in Robinson's (2001b) map task, the participants that were familiar with the simple campus map and unfamiliar with the Tokyo street map and familiarity led the learners to produce more fluent discourse with the campus map task and more complex discourse with the street map task.

Rahimpour and Hazar (2007), also, found that the topic familiarity had positive effects on accuracy and fluency but negatively affects structural complexity. They operationalized fluency as the number of words per minute and accuracy by calculating the percentage of error-free clauses in the total number of clauses. In order to measure complexity, the ratio of lexical to grammatical words was calculated. They further argued that the need to consider topic familiarity as a task feature in syllabus design and material development and necessity of considering this task feature for accomplishing accuracy, complexity, or fluency in oral task production.

Overall then, Lee (2007) suggested that one way to address the attentional imbalance created by the tension between form and meaning during L2 processing might be to employ culturally familiar topics. Lee further contents that familiar topics are able to bridge the reader and the text by providing prior knowledge.

To sum up, the findings for topic familiarity lend support to an input processing model of SLA, as outlined in Van Patten (2004). This model proposes a series of principles that attempt to account for how L2 learners establish formmeaning connections during comprehension and why learners make some form-meaning connections and not others (VanPatten, 2004:1).

\section{+/- Single Task}

By +/- single task, Robinson (2007c) means, tasks requiring only one thing to be done versus those requiring two (dual), or many (multiple) things to be done simultaneously. To investigate this dimension of task complexity, Robinson and Lim (1993) operationalized '+/- single task' using a one-way interactive direction-giving task requiring speakers to give directions from point $\mathrm{A}$ to point $\mathrm{B}$ on a map to a partner. In the single task condition the route was marked on the map for the speaker, while in the dual task condition the route was not marked, following the thinking that in this latter condition the speaker would have to both think up the route and describe it (two task) compared to simply describing an identified route (one task). Production on the route-not-marked map task was less fluent than on the route-marked task, with no differences for accuracy and complexity.

\section{CONCLUSIONS}

It is widely accepted that information about the manipulating the complexity of tasks can be used to guide decisionmaking about sequencing in task-based approaches to syllabus construction (Rahimpour, 1997, 1999; Robinson, 2001b, 2003b, 2005a). Robinson (2001b) and Gilabert (2005) have, also, made a case for basing sequencing decisions in taskbased approaches to syllabus design on distinctions between the cognitive demands of tasks which contribute to their relative complexity. Having demonstrated that the complexity of tasks exert a considerable influence on learner 
production, Robinson (2001b) argued that sequencing tasks on the basis of their cognitive complexity is to be preferred over sequencing decisions based on task difficulty or task conditions.

\section{REFERENCES}

[1] Albert, A. and Kormos, J. (2004). Creativity and narrative task performance; an explanatory study. Language Learning, $54: 2,227-310$

[2] Allwright, D. (1984). Why don't learners learn what the teachers teach? The interaction hypothesis. In D. Singleton and D. Little (Eds.). Language learning in formal and informal contexts (pp.3-18). Dublin. IRAAL.

[3] Anderson, A. \& Lynch, T. (1988). Listening. Oxford: Oxford University Press.

[4] Brindley, J. (1987). Factors affecting task difficulty. In D. Nunan, (Ed.), Guidelines for the development of curriculum resource (pp.45-56). Adelaide: National Curriculum Resource Center.

[5] Brown, R., \& Bellugi, U. (1964). 'Three processes in the child's acquisition of syntax'. Harvard Educational Review. 34: 133151.

[6] Brown, G. \& Yule, G. (1983). Teaching the spoken language. Cambridge: Cambridge University Press.

[7] Bygate, M. (1999). Task as context for framing, reframing, and unframing of language. System, 27, 33-48.

[8] Bygate, M., Skehan, P. \& Swain, M. (2001). Introduction' In M.Bygate, P. Skehan and M. Swain (Eds.). Researching pedagogic tasks, second language learning, teaching and testing. Harlow: Longman.

[9] Candlin, C. (1987). Towards task-based language learning. In Candlin, C. \& Murphy, D. (Eds.), Language learning tasks (pp.5-22). Englewood Cliffs, NJ: Prentice Hall.

[10] Crabbe, D. (2007). Learning opportunities: adding learning value to tasks. ELT Journal, 61/2. 117-125.

[11] Crooks, G. (1989). Planning and interlanguage variation, Studies in Second Language Acquisition, 11, 367-383.

[12] Ellis, R. (1993). 'Second language acquisition and the structural syllabuses.' TESOL Quarterly 27: 91-113.

[13] Ellis, R. (1994). The study of second language acquisition. Oxford: Oxford University Press.

[14] Ellis, R. (2003). Task-based language learning and teaching. Oxford: Oxford University Press.

[15] Ellis, R (Ed.) (2005). Planning and task performance in a second language. Amsterdam: John Benjamins.

[16] Ellis, R. \& Barkhuizen, G. (2005). Analyzing learner language. Oxford: Oxford University Press.

[17] Foster, P. (1999). Task-based learning and pedagogy. ELT Journal, 53(1), 69-70.

[18] Foster, P., \& Skehan, P. (1996). The influence of planning and task type on second language performance. Studies in Second Language Acquisition, 9, 12-20.

[19] Foster, P., \& Skehan, P. (1999). The influence of planning and focus of planning on task-based performance. Language Teaching Research, 3, 215-247.

[20] Gilabert, R. (2005). Task complexity and L2 narrative oral production. Unpublished Ph. D. Dissertation. University of Barcelona, Spain.

[21] Gilabert, R. (2007). Effects of manipulating task complexity on self-repair during L2 oral production. IRAL (45), $215-240$.

[22] Givon, T. (1989). Mind, code, and context. essays in pragmatics. Hillsdale, NJ:Erlbaum.

[23] Hardy, I., \& Moore, J. (2004). Foreign language student's conversational negotiations in different task environments. Applied Linguistics, 25: 340-370.

[24] Kumaravadivelu, B. (2006). TESOL methods: changing tracks, challenging trends, TESOL Quarterly, 40(1), 59-81.

[25] Lantolf, J (Ed.). (2000). Sociocultural theory and second language learning. Oxford: Oxford University Press.

[26] Lee, S. (2007). Effects of textual enhancement and topic familiarity on Korean EFL students' reading comprehension and learning of passive form. Language Learning. 57: 1, 87-118.

[27] Leeser, M.J. (2007). Learner-based factors in L2 reading comprehension and processing grammatical form: topic familiarity and working memory, Language Learning, 57:2; 229-270.

[28] Long, M. H. (1985). A role for instruction in second language acquisition: task-based language teaching. In K. Hyltenstam and M. Pienemann (Eds.), Modeling and assessing second language acquisition (pp.77-99). Clevedon: Multilingual Matters.

[29] Long, M. H. (1996). The role of linguistic environment in second language acquisition. In W.C.Ritchie\& T.K.Bhatia (Eds.). Handbook of second language acquisition. (pp.413-463). San Diego; Academic Press.

[30] Long, M. (Ed.) (2007). Problems in SLA, Mahwah, NJ: Erlbaum.

[31] Long, M. H. \& Crookes, G. (1992). Three approaches to task-based syllabus design, TESOL Quarterly, 26(1), 27-56.

[32] Long, M. H., \& Robinson, P. (1998). 'Focus on form: theory, research, and practice' In C. Doughty and j. Williams. (Eds.). Focus on form in classroom second language acquisition. (pp. 15-41). Cambridge: Cambridge University Press.

[33] Lynch, T., \& MacLean, J. (2000). Exploring the benefits of task repetition and recycling for classroom language learning, Language Teaching Research, 4, 221-250.

[34] Meisel, J. (1987). Reference to past events and actions in the development of natural language acquisition. In C. Pfaff (Ed.), First and second language acquisition processes (pp.206-224). Cambridge, MA: Newbury House.

[35] Michel, M. Kuiken, F., \& Vedder, I. (2007). The influence of complexity in monologic versus dialogic tasks in Dutch L2. IRAL, $45,241-259$.

[36] Mitchell, R., \& Myles, F. (2003). Second language learning theories. London: Hodder.Arnold.

[37] Mortazanejad, S. (2008). L2 learner performance in planned vs. unplanned condition. Unpublished M.A. dissertation. University of Tabriz, Iran.

[38] Niwa, Y. (2000). Reasoning demands of L2 tasks and L2 narrative production: Effects of individual differences in working memory, intelligence, and aptitude. Unpublished M.A dissertation, Ayoama Gakiun University, Tokyo.

[39] Nunan, D. (1989). Designing tasks for the communicative classroom. Cambridge: Cambridge University press.

[40] Nunan, D. (2003). Second language teaching and learning. Boston, U.S.A: Newbery house. 
[41] Philip, j., Oliver, R. \& Mackey, A. (2006). The impact of planning time on children's task-based interactions, System, 34, 565-574.

[42] Prabhu, N. S. (1987). Second language pedagogy. Oxford: Oxford university press.

[43] Philip, J., Oliver, R. \& Mackey, A. (2006). The impact of planning time on children's task-based interactions. System, 34, 574565.

[44] Rahimpour, M. (1995). Interlanguage variation and task performance: an analysis of accuracy, complexity and fluency of second language speech production. Paper presented at the annual conference of ALAA, Australian National University, Canberra, 26-29. September, 1995.

[45] Rahimpour, M. (1997). Task complexity, task condition and variation in L2 oral discourse. Unpublished PhD Thesis. The University of Queensland, Brisbane, Australia.

[46] Rahimpour, M. (1999). Task complexity and variation in interlanguage. In N. Jungheim \& P. Robinson (Eds.), Pragmatics and Pedagogy: Proceedings of the $3^{\text {rd }}$ Pacific Second Language Research Forum, 2, 115-134, Tokyo: PacSLRF.

[47] Rahimpour, M. (2001a). The role of classroom teacher in syllabus design. Paper presented at TDTR $5^{\text {th }}$ international conference 9-11 sep.2001 Middle East Technical University of Ankara, Turkey.

[48] Rahimpour, M. (2002b). Factors affecting task difficulty. Journal of Faculty of letters and humanities, Teachers Training University; Tehran, 9, 1-16.

[49] Rahimpour, M. (2002d) Task-based syllabi. Paper presented at AILA conference 16-21, December, 2002. Singapore.

[50] Rahimpour, M. (2005). The impact of task types on L2 learners' performance. Paper presented at $13^{\text {th }}$ World conference of applied linguistics. University of Wisconsin, U.S.A, 24-29, July.

[51] Rahimpour, M. (2007). Task complexity and variation in L2 oral discourse. Working Papers in Linguistics 1, 1-9. The University of Queensland, Brisbane, Australia.

[52] Rahimpour, M. (2008). Implementation of task-based approaches to language teaching Pazhuhesh-e-zabanha-ye Khareji, No.41, Special Issue, English, pp. 45-61.

[53] Rahimpour, M. \& Hazar, F. (2006). Task condition and interlanguage variation: An investigation of the impact of interactional feedback. Paper presented at pacSLRF2006 July, 4-6: The University of Queensland, Brisbane, Australia.

[54] Rahimpour, M. \& Hazar, F. (2007). Topic familiarity effect on accuracy, complexity, and fluency of L2 oral output, The Journal of ASIA TEFL, 4(4), 191-211.

[55] Richards, J. C. \& Rodgers, T. S. (2001). Approaches and methods in language teaching. Cambridge: Cambridge University Press.

[56] Robinson, P. (1995a). Task complexity and second language narrative discourse, Language Learning, 45(1), 99-140.

[57] Robinson, P. (1995b). Attention, memory and the "noticing" hypothesis. Language Learning. 45: 283-331.

[58] Robinson, P. (1996). Task complexity and second language syllabus design: data-based studies and speculations. Working papers in language and linguistics, 1(1), 1-15

[59] Robinson, P. (1998). State of the art: SLA theory and second language syllabus design. The Language Teacher, 22(4). 7-14.

[60] Robinson, P. (2000). Task complexity and reasoning demands: effects on dyadic NNS- NNS interaction, fluency, accuracy, complexity and incorporation of input. Unpublished data, Aoyama Gakuin University, Tokyo.

[61] Robinson, P. (2001a). Task complexity, task difficulty, and task production: exploring interactions in a componential framework. Applied Linguistics, 22, 27-57.

[62] Robinson, P. (2001b). Task complexity, cognitive resources, and syllabus design: A triadic framework for examining task influences on SLA. In P. Robinson (Ed.), Cognition and second language instruction (pp.285-316). Cambridge: Cambridge University Press.

[63] Robinson, P. (2003b). The cognition hypothesis, task design, and adult task-based language learning. Second Language Studies, 21(2), 45-105.

[64] Robinson, P. (2005a). Cognitive complexity and task sequencing: A review of studies in a componential framework for second language task design. International Review of Applied Linguistics in Language Teaching. 43(1): 1-33.

[65] Robinson, P. (2007a). Criteria for grading and sequencing pedagogic tasks. In investigating tasks in formal language learning, Maria Del Pilar Garcia Mayo (Ed.), 2-27. Clevedon: Multilingual Matters.

[66] Robinson, P. (2007c). Task complexity, theory of mind, and intentional reasoning: Effects on L2 speech production, interaction, uptake and perceptions of task difficulty. IRAL, 193-213.

[67] Robinson, P., \& Gilabert, R. (2007). Task complexity, the Cognition Hypothesis and second language learning and performance. IRAL 45, 161-176.

[68] Robinson, p., \&. Lim, J. J. (1993). Cognitive load and the rout-marked not marked map task. Unpublished data, University of Hawaii at Manoa, Department of ESL, Honolulu, USA.

[69] Schmidt, R. (1990). The role of consciousness in second language learning. Applied Linguistics.11: 17-46.

[70] Schmidt, R. (2001). Attention in P. Robinson (Ed.): Cognition and second language instruction. (PP. 3-32). Cambridge: Cambridge University Press

[71] Sheen, Y. (2004). Corrective feedback and learner uptake in communicative classrooms across instructional settings. Language Teaching Research, 8, 263-300.

[72] Skehan, P. (1996). A framework for the implementation of task-based instruction. Applied Linguistics, 17(1), 38-62.

[73] Skehan, P. (1998a). Task-based instruction. Annual Review of Applied Linguistics, 18, 268-286.

[74] Skehan, P. (1998b). A cognitive approach to language learning. Oxford: Oxford University Press.

[75] Skehan, P. (2002). A non-marginal role for task. ELT Journal. 56/3, 289-295.

[76] Skehan, P. (2003a). Focus on form, tasks, and technology. Computer Assisted Language Learning, 16/5, pp. 391-411.

[77] Skehan, P. (2003b). Task-based instruction, Language Teaching, 36, 1-14.

[78] Skehan, P., \& Foster, P. (1997). Task type and task processing conditions as influences on foreign language performance. Language Teaching Research, 1(3), 1-27. 
[79] Skehan, P., \& Foster, P. (2001).Cognition and tasks. In' Cognition and second language instruction,' P. Robinson (Ed.), 183205. Cambridge: Cambridge University Press.

[80] Swain, M. (1985). 'Communicative competence: some roles of comprehensive input and comprehensive output in its development' in S. Gass and C. Madden (Eds.), Input in Second language acquisition (pp.235-253). Rowley, MA: Newbury House.

[81] Swain, M. (1995). Three functions of output in second language. In H.G. Widdowson, G.Cook \& B. Seidlhofer (Eds.), Principles and practice in applied linguistics: studies in honor of H. G. Widdowson (pp.125-144). Oxford: Oxford University Press.

[82] Swain, M. (2000). The output hypothesis and beyond: Mediating acquisition through collaborative dialogue. In J. Lantolf (Ed.), sociocultural theory and second language learning (pp. 97-114). Oxford: Oxford University Press.

[83] Swain, M., \& Lapkin, S. (1995). Problems in output and cognitive processes they generate: A step towards second language learning. Applied Linguistics. 16(3), 371-391.

[84] Tavakoli, P., \& Foster, P. (2008). Task design and second language performance: the effect of narrative type on learner output. Language Learning. 58:2, 439-473

[85] Urwin, J. (1999). Second language listening task complexity. Unpublished Ph.D. dissertation, Monash University, Australia.

[86] Van den Branden, K. (Ed.) (2006). Task-based language education. Cambridge: Cambridge University press.

[87] VanPatten, b. (1990). 'Attending to form and content in the input'. Studies in Second Language Acquisition, 12: $287-301$.

[88] Van Patten, B. (2004). Input processing in SLA. In Van Patten (Ed.), Processing instruction Theory, research, and commentary (pp.5-31). Mahwah, NJ: Lawrence Erlbaum

[89] Widdowson, H. G. (2003). Defining issues in English language teaching. Oxford: Oxford University Press.

[90] Willis, D. \& Willis, J. (2001). Task-based language learning. In D, Nunan. \& Carter, R. (Eds.), The Cambridge guide to teaching English to the speakers of the other languages (pp.173-179). Cambridge: Cambridge University Press.

[91] Wilkins, D. (1976). Notional syllabuses. Oxford: Oxford University Press.

[92] Yuan, F. \& Ellis, R. (2003). The effect of pre-task planning and on-line planning on fluency and complexity and accuracy in L2 monologic oral production. Applied Linguistics, 24(1), 1-27.

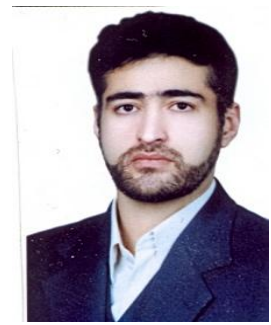

Ebrahim Ghorban Mohammadi is currently a $\mathrm{PhD}$ candidate in Teaching English as a Foreign Language in Islamic Azad University, Khorasgan (Isfahan) Branch. He has published papers in domestic and international journals. His areas of interest include pronunciation and vocabulary acquisition, EFL reading and writing, language assessment, and psycholinguistics.

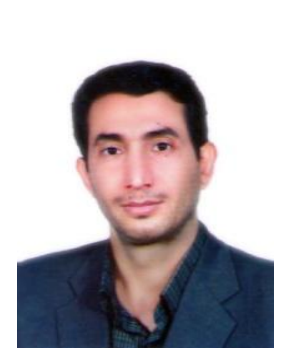

Mohammad Hossein Yousefi is currently doing his $\mathrm{PhD}$ at the Islamic Azad University of khorasgan Isfahan), Iran. His main research interests are; Task-based Language Teaching, Cognitive Complexity, Corrective Feedback, and SLA. He, also, teaches ESP for undergraduate students at the Islamic Azad University of Bonab, Iran.

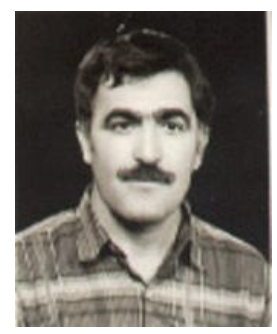

Akbar Afghari received his Ph.D. from Stanford University, USA in 1984. His research interests are: applied linguistics, testing, sociolinguistics, and discourse analysis. He has published a number of articles and books on these fields. 